A. A. Kud

\title{
Methodology for Determining Whether a Blockchain Token Corresponds to a Digital Asset
}

\author{
Methodical Manual
}

Kharkiv

"KRPOCH"

2019 
UDC 001.891.5:330.47:33.053.22(072)

DOI $10.26697 / 9786177089079.2019$

K 88

Recommended for publication by the scientific and methodological council of the Research Institute KRPOCH

(Protocol No. 01 dated March 30, 2019)

\section{Reviewers:}

Kucheriavenko N. P. - Doctor of Legal Science, Candidate of Economic Sciences, Professor, Head of the Department of Financial Law of the Yaroslav Mudryi National Law University, First Vice-President of the National Academy of Legal Sciences of Ukraine.

Marchenko O. S. - Doctor of Economic Sciences, Professor, Professor of the Department of Economic Theory of the Yaroslav Mudryi National Law University.

Makarichev A. V. - Doctor of Physics and Mathematics, Associate Professor, Professor of the Department of Transport Technologies and Technical Services of the Institute of Mechanics of NUWEE, Lead Researcher of the Department of Transport Systems and Logistics of KNAHU.

Kud A.A. Methodology for Determining Whether a Blockchain Token Corresponds to a Digital Asset: methodical manual / Scientific Research Institute KRPOCH. Kharkiv: KRPOCH, 2019. 52 p. doi: 10.26697/9786177089079.2019 ISBN 978-617-7089-07-9

The publication provides criteria and indicators of the characteristics of a blockchain token, presents the methodology for determination and mathematical processing of data. The methodological manual has been developed in order to establish whether a blockchain token is a digital asset based on the results of its research, including the research of the legal characteristics of a blockchain token, and is intended for specialists in the fields of information and digital economy, lawyers, financial organizations and representatives of business communities.

UDC 001.891.5:330.47:33.053.22(072)

ISBN 978-617-7089-07-9

(C) Kud A.A., 2019

(C) KRPOCH, 2019 


\section{CONTENTS}

INTRODUCTION

SECTION 1. THEORETICAL BASIS

OF A BLOCKCHAIN TOKEN AS A DIGITAL ASSET

1.1. Development of the Blockchain Technology:

Cryptocurrencies, Tokens, Digital Assets

1.2. Complex of Definitions of the Basic Concepts Related to

a Blockchain Token

1.3. Components in the Context of the Definition of the Term "Digital Asset"

1.4. Characteristics of the Criteria and Indicators of a

Blockchain Token's Correspondence to a Digital Asset

SECTION 2. ORGANIZING AND CONDUCTING THE RESEARCH OF CHARACTERISTICS

OF A BLOCKCHAIN TOKEN

2.1. Research of Characteristics of a Blockchain Token 25

2.2. Analysis of Research Results $\quad 28$

2.3. Interpretation of Research Results

SECTION 3. MATHEMATICAL FORMALIZATION

OF METHODOLOGY FOR DIAGNOSING WHETHER

CHARACTERISTICS OF A BLOCKCHAIN TOKEN

CORRESPOND TO THOSE OF A DIGITAL ASSET

3.1. Triple Classification Based on the Results of the

Diagnostics on Whether a Blockchain Token Corresponds to a Digital Asset

3.2. Reliability of the Methodology for Diagnosing the

Blockchain Token Based on the Number of Points Received

CONCLUSIONS

THESAURUS

43

REFERENCES 


\section{INTRODUCTION}

The modern global financial system is going through significant changes, which are caused largely by the formation of its new field the information economy based on the blockchain technology.

The implementation and development of the distributed ledger technology similar to account books, each of which has the same data records and is jointly supported and controlled by a distributed network of computer servers, have contributed to the emergence of a new technology - blockchain.

Today, the blockchain technology is considered by society as a new mechanism for the dissemination of digital information. In particular, it attracts financial experts, who first became interested in blockchain as the technology of an account book, but then realizing its enormous potential, started creating digital currencies on its basis and looking for other ways of its application. The active implementation of the blockchain technology and the revealed advantages of its application reflect global transformations, which affect political, legal, socioeconomic and other areas of social life.

Thus, it becomes obvious that the sooner institutions and organizations, both governmental and non-governmental, can use this technology to optimize their activities, the more innovative and competitive their products and services will become. The use of blockchain tokens for registration and exchange of property rights to assets and, generally, of any kind of rights, will lead to a drastic transformation in various fields, comparable in importance to the replacement of typewriters by computers, not to mention the optimization of processes related to accounting and information exchange by means of digital assets.

The main objectives of this manual are: to display the characteristics of a blockchain token that are laid down in the term "digital asset"; define criteria and indicators of characteristics of a blockchain token; present a methodology for diagnosing a blockchain token for correspondence to a digital asset and a method for mathematical data processing for such evaluation.

Thus, this methodological manual will allow you to establish the correspondence of any blockchain token to a digital asset. 


\section{SECTION 1 \\ THEORETICAL BASIS \\ OF A BLOCKCHAIN TOKEN AS A DIGITAL ASSET}

\subsection{Development of the Blockchain Technology: Cryptocurrencies, Tokens, Digital Assets}

The development of the digital economy as a whole, and of digital technologies in particular, has led to the emergence of a new term "digital asset" and to the stage-by-stage implementation of related processes.

The use of the term "digital asset" in the modern understanding is primarily caused by the emergence of the blockchain technology and cryptocurrencies.

Blockchain is a particular type or subset of the so-called distributed ledger technology (DLT). This technology is a mechanism that employs an encryption method known as cryptography and a set of specific mathematical algorithms to create and verify a constantly growing data structure, to which you can add data and from which you cannot delete the existing data - the form of a chain of "transaction blocks", which functions as a distributed ledger.

In simple terms, blockchain can be considered as a distributed database. Additions to this database are initiated by one of the network nodes, which creates a new block of data that can contain various types of information. This new block is transmitted to every party in the network (using cryptography). Other nodes collectively determine the block's validity in accordance with a predefined method of algorithmic validation, commonly referred to as a "consensus mechanism". Once validated, the new block is added to the chain of blocks of the public distributed ledger (blockchain), which, essentially, results in an update of the transaction ledger and is distributed across the network.

One of the key advantages of the blockchain technology is that it allows simplifying the execution of a wide array of transactions that usually require third-party intermediaries, i.e. eliminating intermediaries from the process of interaction between the two parties. 
Despite the fact that the blockchain technology is often associated with digital or virtual currency schemes, payments and financial services, its scope of use is much wider. In practice, blockchain is already used in various sectors (e.g. trade and commerce, healthcare, public administration, logistics, banking, etc.).

It should be noted that cryptocurrency is the first well-known application of the blockchain technology, which formed the basis of the cryptocurrency market and resulted in the whole variety of cryptocurrencies. At the same time, it can be noted today that blockchain has clearly outgrown the cryptocurrency context and, as a technology, it can be applied in many areas of social life.

Since the emergence of the first virtual currency in 2009, the topic of cryptocurrencies and blockchain has been studied by various international organizations and state institutions, each of which approached it differently. The fundamental documents for clarifying the essence of the terms under consideration are official publications of international regulatory and supervisory bodies in this area.

The European Central Bank (ECB) classified cryptocurrencies as a subgroup of virtual currencies. In its report on virtual currency schemes in 2012, the ECB defined such currencies as a type of unregulated, digital money, which is issued and usually controlled by its developers, and used and accepted among the members of a specific virtual community.

The ECB further clarified that three types of virtual currencies can be distinguished depending on the interaction with traditional currencies and the real economy:

1) virtual currencies, which can only be used in closed virtual systems, usually in online games;

2) virtual currencies that are unilaterally linked to the real economy: there is a conversion rate for purchasing currency (with traditional money), and the purchased currency can subsequently be used to purchase virtual or real goods and services;

3) virtual currencies that are bilaterally linked to the real economy: there are conversion rates both for purchasing and selling such currency; the purchased currency can be used to purchase both virtual and real goods and services [1, p. 13-19]. 
In a more recent report of 2015, the ECB put forward another, largely updated, definition of virtual currencies. It defined virtual currencies as digital representations of value not issued by a central bank, credit institution or e-money institution, which in some circumstances can be used as an alternative to money [2, p. 4].

Like the ECB, the International Monetary Fund (IMF) has categorized cryptocurrencies as a subset of virtual currencies, which it defines as digital representations of value issued by private developers and denominated in their own unit of account. [3, p. 7].

According to the IMF, the concept of virtual currencies covers a wider array of currencies ranging from simple derivative financial instruments (IOUs) of virtual currencies, which are backed by various assets such as gold or real property, to electronic money and cryptocurrencies.

The Committee on Payments and Market Infrastructures (CPMI), a body of the Bank for International Settlements (BIS), has defined cryptocurrencies as digital currencies or digital currency schemes.

These schemes have the following key features:

- they are assets whose value is determined by supply and demand, similar in concept to commodities such as gold, but with zero intrinsic value;

- they use a distributed ledger, which allows remote peer-topeer exchange of electronic values in the absence of trust between the parties and without the need for intermediaries;

- they are not operated by any specific individual or institution [4, p. 4-7].

The European Banking Authority (EBA) has proposed to refer to cryptocurrencies as virtual currencies, which it defines as digital representations of value that are neither issued by a central bank or a public authority, nor necessarily attached to a fiat currency, but are used by natural or legal persons as a means of exchange and can be transferred, stored or traded electronically [5, p. 11].

The European Securities and Markets Authority (ESMA) also refers to cryptocurrencies as virtual currencies in a pan-European warning issued in cooperation with the European Insurance and 
Occupational Pensions Authority (EIOPA) and the EBA. Fully in line with the EBA's definition, virtual currencies are defined as digital representations of value that are neither issued nor guaranteed by a central bank or public authority and do not have the legal status of currency or money $[6$, p. 1$]$.

The World Bank has classified cryptocurrencies as a subset of digital currencies, which it defines as digital representations of value that are denominated in their own unit of account, distinct from emoney, which is simply a digital payment mechanism, represented and denominated in fiat money. The World Bank has also defined cryptocurrencies as digital currencies that rely on cryptographic methods to achieve consensus [7].

The Financial Action Task Force (FATF) as an intergovernmental organization, which sets world standards for combating money laundering and financing of terrorism, has approached cryptocurrencies as a subset of virtual currencies, which it defines as digital representations of value that can be digitally traded and function as a medium of exchange; and/or a unit of account; and/or a store of value, but do not have legal tender status in any jurisdiction. Thus, virtual currencies can be divided into two basic types:

- convertible virtual currencies that have an equivalent value in real currency and can be exchanged back-and-forth for real currency; these virtual currencies can be of a centralized or a decentralized nature (i.e. they can either have a central administrative authority that controls the system or no central oversight at all);

- non-convertible virtual currencies that are specific to a particular virtual domain or world, and under the rules governing its use, cannot be exchanged for fiat currency [8, p. 4-5].

The properties and functions of some blockchain tokens resemble the properties and functions of traditional financial instruments, such as shares or bonds, and are commonly referred to as "security tokens" or "investment tokens". Other blockchain tokens provide their owners with access to specific products or services and are commonly referred to as "utility tokens". They can be used to acquire certain products or services, but they do not constitute a 
general-purpose medium of exchange, because, as a rule, they can generally only be used on the token platform itself.

The distinctive feature of the legal regulation of these relations is associated with the coordination of regulation of virtual currency circulation at the national and international levels. In these conditions, regulation of the virtual currency circulation is associated with a certain duality of coordination. Firstly, we are talking about combining the regulation of these relations both within the framework of national legislation and at the international level. Secondly, social relations that have to do with the circulation of virtual currencies are complex in nature, providing both their regulation by means of private and public law, and the allocation of certain aspects of these relations as the subject of civil, economic and financial law.

The multi-level correlation of regulatory requirements within one country also adds some complexity. In 2017, the Uniform Law Commission (ULC) developed the Uniform Regulation of VirtualCurrency Business Act, a unified act on the regulation of activities related to virtual currencies. Economic activities related to virtual currencies and specified in this act are identical to services that are already subject to licensing and prudential regulation in the status of "money providers" or "money transfers" in many states. In 2018, this act was supplemented by the Uniform Supplemental Commercial Law for the Uniform Regulation of Virtual-Currency Businesses Act, a unified act on commercial law for the uniform regulation of virtual currencies.

The peculiarity of such uniform acts is that they are not automatically included either in the US federal law or in the legislation of the federal subjects. These acts are guidelines for policy makers in the process of legislation development in the relevant field.

A significant number of negative aspects of the application of virtual currencies are associated with the lack of a legal assessment of this phenomenon and the uncertainty of their legal nature, which greatly complicates the development of an appropriate regulatory framework.

Today, there is no single well-established approach to the content of the term "virtual currency" at either international or national 
levels. In various circumstances, it is defined as money, electronic money, currency, financial instrument, means of payment, medium of exchange, type of digital money, digital representation of value, type of asset, intangible asset, etc. The lack of clarity in the definition of a virtual currency is also supplemented by numerous identical concepts. Along with virtual currency, such concepts as "cryptocurrency", "cryptoasset", and "digital financial asset" are used.

The main conclusion that can be drawn from the foregoing is that there is no generally accepted definition of the term "cryptocurrency" available in the regulatory space. Most government agencies and international organizations have refrained from defining the term altogether. Among those mentioned above, only the World Bank and the FATF have proposed a clear-cut definition. However, it is evident that most of the mentioned institutions and organizations approach cryptocurrencies as a subset or a form of virtual or digital currencies. 


\subsection{Complex of Definitions of the Basic Concepts Related to a Blockchain Token}

The research works of scientists in the economic, financial and legal fields, as well as practitioners in the field of information technology, who employ various definitions of terms "digital currency", "virtual currency", "cryptocurrency", "digital asset", "virtual asset", "cryptoasset", "digital money", "virtual money", "electronic money", constituted the theoretical value and practical significance for the development of the conceptual and categorical apparatus. These terms are not identical and have their own essential features.

Table 1 presents a complex of definitions of the basic terms related to a blockchain token.

Table 1

\section{Complex of Definitions}

\begin{tabular}{|l|l|}
\hline \multicolumn{1}{|c|}{ Term } & \multicolumn{1}{c|}{ Definition } \\
\hline Cryptocurrency & $\begin{array}{l}\text { Special kind of electronic money whose } \\
\text { functioning is based on a decentralized mechanism } \\
\text { of issue and circulation and is a complex system of } \\
\text { information and technological procedures based } \\
\text { on cryptographic protection methods regulating } \\
\text { the identification of owners and recording the fact } \\
\text { of their change [10] }\end{array}$ \\
\hline Cryptocurrency & $\begin{array}{l}\text { Digital currency, which uses encryption } \\
\text { techniques to regulate the generation of units of } \\
\text { currency and verify the transfer of funds, and } \\
\text { operates independently of a central bank [11] }\end{array}$ \\
\hline Cryptocurrency & $\begin{array}{l}\text { Digital currency built with cryptographic } \\
\text { protocols that make transactions secure and } \\
\text { difficult to counterfeit, it is not controlled by any } \\
\text { central authority; facilitates execution of any } \\
\text { transaction, as transfers are simplified by using } \\
\text { public and private keys for security and privacy } \\
\text { purposes [12] }\end{array}$ \\
\hline
\end{tabular}




\begin{tabular}{|c|c|}
\hline Term & Definition \\
\hline Cryptocurrency & $\begin{array}{l}\text { Digital or virtual currency that uses cryptography } \\
\text { for security [13] }\end{array}$ \\
\hline Cryptocurrency & $\begin{array}{l}\text { Universal, virtual, decentralized and convertible } \\
\text { digital currency unit, which can be used to make } \\
\text { payments for real goods, works, services, and } \\
\text { which can be a system of savings, storage and } \\
\text { investment of funds, which is protected by a } \\
\text { cryptographic code, and everyone can issue it, } \\
\text { retaining their anonymity, and the data on } \\
\text { settlements available to each participant cannot be } \\
\text { falsified [14] }\end{array}$ \\
\hline Cryptocurrency & $\begin{array}{l}\text { Digital asset that functions as a medium of } \\
\text { exchange and is very similar to digital cash [15] }\end{array}$ \\
\hline Cryptocurrency & $\begin{array}{l}\text { Digital asset designed to facilitate decentralized } \\
\text { financial transactions and smart contracts on the } \\
\text { Internet; it was first accomplished by solving the } \\
\text { problem of "double-spending" and by using } \\
\text { advanced cryptography and programming; is a } \\
\text { distributed financial ledger used worldwide [16] }\end{array}$ \\
\hline Cryptocurrency & $\begin{array}{l}\text { Information asset, which is the result of } \\
\text { production, commercial and financial activities of } \\
\text { the enterprise, and is on its balance sheet, as well } \\
\text { as ensures the achievement of its intended goals; } \\
\text { information asset is a communication tool of } \\
\text { financial and economic relations whose } \\
\text { functioning is based on modern information } \\
\text { technologies, telecommunication systems, } \\
\text { cryptography, etc., controlled by the enterprise as } \\
\text { a result of past events and the use of which is } \\
\text { expected to result in future economic benefits [17] }\end{array}$ \\
\hline Cryptocurrency & $\begin{array}{l}\text { Digital medium that can be exchanged, like } \\
\text { government currencies, and which uses } \\
\text { cryptography or digital security measures to secure } \\
\text { the exchange of digital information and to control } \\
\text { the creation of new units; a digital coin whose }\end{array}$ \\
\hline
\end{tabular}




\begin{tabular}{|c|c|}
\hline Term & Definition \\
\hline & $\begin{array}{l}\text { value fluctuates the same way as stocks' value, and } \\
\text { its exchange is backed by digital security } \\
\text { measures [18] }\end{array}$ \\
\hline $\begin{array}{l}\text { Virtual } \\
\text { currency }\end{array}$ & $\begin{array}{l}\text { Created property, which is accounted through the } \\
\text { use of information and telecommunication } \\
\text { technologies; not denominated in the currency of } \\
\text { states, can be used by an indefinite number of } \\
\text { persons to make payments, is not electronic money } \\
\text { and legal tender [19] }\end{array}$ \\
\hline Cryptoasset & $\begin{array}{l}\text { Cryptographically secured digital representation } \\
\text { of value or contractual rights that uses a particular } \\
\text { type of the distributed ledger and can be } \\
\text { transferred, stored or traded electronically [20] }\end{array}$ \\
\hline Cryptoasset & $\begin{array}{l}\text { Digital representations of value made possible by } \\
\text { advances in cryptography and the distributed } \\
\text { ledger technology; cryptoassets are denominated } \\
\text { in their own units of account and can be transferred } \\
\text { peer-to-peer without intermediaries [21] }\end{array}$ \\
\hline Virtual asset & $\begin{array}{l}\text { Representation of currency in some environment } \\
\text { or situation. In this context, currency can be } \\
\text { defined as either a medium of exchange or a } \\
\text { property that has value in a specific environment. } \\
\text { Monetary virtual assets are often called virtual } \\
\text { currency [22] }\end{array}$ \\
\hline Virtual asset & $\begin{array}{l}\text { Any form of record within a distributed ledger of } \\
\text { records in a digital form that can be used as a } \\
\text { medium of exchange, unit of account or as a means } \\
\text { of value preservation [23] }\end{array}$ \\
\hline Digital asset & $\begin{array}{l}\text { Any text or media that is formatted into a binary } \\
\text { source and includes the right to use it; digital files } \\
\text { that do not include this right are not considered } \\
\text { digital assets [11] }\end{array}$ \\
\hline Digital asset & $\begin{array}{l}\text { Digitally stored content (images, photos, videos, } \\
\text { files containing text, spreadsheets or slide decks) } \\
\text { is any content in any format that is stored digitally }\end{array}$ \\
\hline
\end{tabular}




\begin{tabular}{|c|l|}
\hline Term & \multicolumn{1}{|c|}{ Definition } \\
\hline Digital asset & $\begin{array}{l}\text { and provides value to the company (user or } \\
\text { consumer) [24] }\end{array}$ \\
\hline Digital asset & $\begin{array}{l}\text { Assemblies of metadata that is getting more } \\
\text { appreciated and complicated the more you connect } \\
\text { them, it also means that they can have a limitless } \\
\text { range of applications; most digital assets have a } \\
\text { fixed monetary value; since they represent the } \\
\text { digitization of elements belonging to the user or } \\
\text { organization; the value of assets usually increases } \\
\text { in accordance with their use [26] }\end{array}$ \\
\hline Electronic & $\begin{array}{l}\text { Full-fledged non-cash payment instrument, a } \\
\text { prepaid financial product that does not have a } \\
\text { connection with a personalized bank account and } \\
\text { gives its holder the right to claim the fulfillment of } \\
\text { a monetary obligation by the electronic money } \\
\text { system operator by returning money previously } \\
\text { provided to it (which acts as coverage), which is } \\
\text { recorded without opening individual bank } \\
\text { accounts [27] }\end{array}$ \\
\hline Electronic \\
money
\end{tabular}


Thus, the modern development of new forms of representing digital technologies is characterized by such a rapid pace that the formation of the corresponding theoretical basis and of the concrete conceptual and categorical apparatus significantly falls behind, which is why scientific publications equate the above-mentioned categories or replace some of them with different ones.

By analyzing the above-mentioned definitions, it can be stated that today there is a substitution of concepts in society, and in most cases, the term "digital asset" means cryptocurrency. Such tendencies can be explained by a rather ambiguous status of cryptocurrencies and, therefore, attempts to minimize the negative attitude towards this phenomenon.

As practice shows, changes in the field of information technology and the economy are occurring very quickly, therefore, the essence and nature of digital assets, which are currently at the stage of development, are not yet fully understood and accepted by the modern community. At the same time, it is necessary to take into account the prospects of using digital assets, since in the future they may become the universally recognized equivalent of value and have the legal tender status. Therefore, any classification and systematization of related concepts is somewhat arbitrary and, in modern rapidly changing conditions, for obvious reasons, cannot be considered established yet. 


\subsection{Components in the Context of the Definition of the Term "Digital Asset"}

Digital asset is still a poorly studied phenomenon for the economy, therefore, the essential distinction from other objects seems extremely necessary in the conditions of the development of the market of information resources and services based on the blockchain technology.

Indeed, based on the foregoing, we can conclude that today the term "digital asset" is interpreted differently, which greatly complicates the understanding of many processes related to the use of digital assets and quite often affects the distortion and misinterpretation of information laid down in the basis of existence of digital assets. Such terminological confusion creates stable conditions for further establishment of the inconsistency and ambiguity not only of the term "digital asset" itself, but also of the prospects for its use. Due to the fact that digital assets have great potential for the real sector of economy, there is a need for their legal regulation and consolidation of the definition of "digital asset" in the economic and legal aspects based on the established essential semantic features [29].

DIGITAL ASSET is an information resource derivative of the right to a value and circulating in the distributed ledger in the form of a unique identifier.

When clarifying the definition of the term "digital asset", certain essential semantic features represented by four components have been analyzed:
1) economic;
2) legal;
3) information;
4) value.

Taking these elements into account, its structural components have been emphasized in the definition of "digital asset".

Economic component in the context of the definition of the term "digital asset" is represented in the financial field by a unique identifier. 
The component "in the form of a unique identifier" indicates the form of representation of a digital asset and the existence of a unique name. The alphanumeric code assigned by the system, in which the digital asset circulates, allows distinguishing a specific digital asset in the distributed ledger and obtaining the necessary information about it. The given properties of a unique identifier of a blockchain token transaction allow individuals and business entities to conduct the balance accounting of a digital asset, which enables them to calculate the main economic indicators of activity, including production of goods, cost of production, profit and profitability.

Digital assets obtained a unique property with the emergence of the distributed ledger technology, whose structure guarantees safe information storage and the possibility of asset verification. Any changes made to the distributed ledger (blockchain) automatically lead to the generation of a new unique identifier, which eliminates the possibility of duplication and illegal use of the asset. The information about a digital asset contains the following characteristics: its location, registration, legal restrictions and other distinctive features and properties. Blockchain provides the conditions for identifying a digital asset by giving it a unique hash code, which allows assigning such an asset to a specific entity.

Legal component in the context of the definition of the term "digital asset" is represented in the legal field by a derivative of the right.

Having analyzed different meanings of the term "derivative", we can conclude the following: all these terms have a certain basic phenomenon, the subject (source), which determines the origin of a derivative. In other words, "derivative" emerges as a result of the transformation of the source (basic phenomenon) and is able to retain basic properties or rely on them. In turn, the properties of derivatives are predetermined by the properties of sources.

The definition of the term "digital asset" uses the subjective approach to interpreting right as the type and measure of a person's possible behavior, which are governed by legal norms.

According to the analysis of the definitions of the component "derivative of the right", we can state that they most fully reflect the 
essence of the principle laid down in the definition of the term "digital asset". A digital asset is not the right to a value in its interpretation, but it has attributes of a derivative of the right to a value.

Information component in the context of the definition of the term "digital asset" is represented in the IT field by an information resource circulating in the distributed ledger.

Information resource is information structured and organized in a certain way and recorded on a tangible medium. Information can be stored, transmitted, used, and updated. An information resource has the properties of practical significance and usefulness as well as the possibility of multiple use ("inexhaustibility"). Unlike other types of resources (natural, economic, temporary), the quantity and quality of information resources increase as they are used. Such a cumulative effect along with the development of modern technologies contributes to the rapid increase in the information potential of society as a whole.

Thus, a digital asset is an information resource in the sense that the information on a value presented in a digital form has such main properties of an information resource as:

a) information is structured according to certain parameters and categories;

b) information is recorded on a digital medium;

c) information can be stored, transmitted, exchanged, used, etc.

In addition, a digital asset has an additional property information on a value is formed by the owner of this value. It should also be noted that an information resource in the context of the definition of the term "digital asset" is deprived of such a characteristic as the possibility of being copied an unlimited number of times. This is due to the fact that in the distributed ledger, each such resource is expressed in the form of a unique identifier, which ensures stable conditions for the guaranteed conformity of a digital asset to a specific entity. Thus, the following important conclusion can be reached: the value of a digital asset lies in its uniqueness and credibility, which are ensured by circulation of the digital asset in the distributed ledger. Based on these characteristics, one can also designate the high practical significance of the digital asset in the economic and legal aspects. 
One of the key properties of a digital asset is the ability to circulate in the digital environment, rather than being copied during transmission from one email address (storage, wallet, cell) to another. A circulating object (digital asset) must necessarily have not only its own circulation environment, but also clearly defined rules and conditions for its existence in such an environment. To be able to establish and monitor the implementation of such rules and conditions, a reliable digital scalable and decentralized ecosystem is needed, which will allow all participants to be confident that the uniqueness of information resources will be preserved. That is why the component "distributed ledger" occupies an important place in the definition of a digital asset.

The distributed data storage system of such ledgers is one of the most technologically advanced. It provides the highest possible level of confidence in the information due to the mandatory procedure of verifying it for accuracy by all nodes of the distributed environment through a certain method of building consensus. Thus, the problem of "double-spending" is also solved. The information contained in such a ledger cannot be deleted or modified, and the reliability and mechanism of this storage method allow creating records on the right to values (assets) in the ledger. This is a necessary procedure in the process of creating a digital asset, which, in turn, requires recording information about the assessment (audit) and other data of the owner of the digitized value in the ledger, including his/her property right to a value. To understand the nature of a digital asset, it is important to take into account the mandatory conditions: the possibility of confirming that a digital asset belongs to a particular entity, as well as the absence of any means of creating a copy of the same digital asset, including by duplicating its unique identifier. Such conditions can only be provided by the distributed ledger technology, which allows guaranteeing the uniqueness of digital asset identifiers and assigning specific identifiers to specific objects.

Thus, it can be concluded that the ability to circulate in the distributed ledger for a digital asset is one of the determining ones. Therefore, the distributed ledger as an information storage system is the only possible environment for the existence and circulation of 
digital assets, which are the numerical expression of the rights and obligations of the owner of the real asset in the space of the distributed ledger.

Value component in the context of the definition of the term "digital asset" is represented in the field of tangible and intangible assets by the "value" component.

Value is relative worth, utility, or importance, which can also be expressed by different measurement units depending on the area of practical use of such a value and the ecosystem in which such a value exists.

The phrase "derivative of the right to a value" is used in the definition of the term "digital asset", since, in essence, digital asset is a kind of a guaranteed right to claim a certain value inherent in this digital asset. In other words, a digital asset serves as a digital display of value. Thus, it is the "value" component that is used in the definition of "digital asset", since it conveys most widely and comprehensively the meaning laid down in the definition.

You can read the full text of the paper: Kud A. A. Substantiation of the Term "Digital Asset": Economic and Legal Aspects. International Journal of Education and Science. 2019. Vol. 2. No. 1. P. 41-52. doi: 10.26697/ijes.2019.1.06. http://culturehealth.org/ijes_ archive/IJES,Vol.2,No1,2019_(6).pdf.

After the theoretical substantiation of the term "digital asset", it is extremely important for practice to determine the criteria and characteristics of a blockchain token as a digital asset. 


\subsection{Characteristics of the Criteria and Indicators of a Blockchain Token's Correspondence to a Digital Asset}

In the scientific literature and in articles of information and analytical nature, you can find a lot of publications that highlight the advantages of a particular type of cryptocurrency based on certain characteristics. These publications are quite different in purpose and content, but they have one thing in common: such publications are often dedicated to the consideration and popularization of a specific cryptocurrency. At the same time, the criteria and indicators that should form the basis of the complex characteristics of a blockchain token are not given.

We have analyzed numerous scientific publications and made the following conclusion on their basis: the main problem in the theoretical and practical field is that the industry of information technology and economy is developing rapidly, and therefore, the proposed criteria for determining the characteristics of a blockchain token should be unified and justified in accordance with existing international economic and legal standards.

It is obvious that in the absence of criteria (a complex or a system of criteria) it is impossible to assess an object, identify problems, determine the degree of its perfection, predict further development, etc.

Considering this, in order to determine the criteria for a blockchain token as a digital asset, it is necessary to establish the most significant features that will allow characterizing the indicators to determine whether a certain object corresponds to a digital asset.

The conducted research allowed us to determine the criteria for the optimal characterization of a blockchain token as a digital asset. The optimality is based on a typology of criteria: global - local; external - internal; maximizing result - minimizing costs.

A multi-criteria analysis of the mentioned above complex of definitions and optimal choice of criteria allowed us to solve the problem of determining the criteria and characteristics of a blockchain token as a digital asset. 
The methodology for diagnosing whether a blockchain token corresponds to a digital asset is based on the principle of equivalence of categories.

The use of a blockchain token is determined by the need to observe the mandatory compliance of its characteristics with fundamental and exhaustive categories for a digital asset in the economic and legal aspects, which correspond to the components that produce the definition of a digital asset.

It should be noted that, according to the principle of equivalence of categories, they are all equal in importance for an objective determination of the correspondence of a blockchain token to a digital asset. This means that if a blockchain token does not correspond to at least one of the categories, then such a blockchain token cannot be considered as a digital asset.

These categories include the following:

1. Definition of a digital asset as an information resource;

2. Determination of the nature of the digital asset as a derivative of the right to a value;

3. Circulation of a digital asset in the distributed ledger;

4. Circulation of a digital asset in the form of a unique identifier.

The principle of equivalence of categories is established by:

1) determining a list of criteria that are sufficient for diagnosing a blockchain token for correspondence to a digital asset;

2) sufficiency of the criteria due to the differentiation of 9 digital asset criteria into four categories depending on the ratio of the criteria to the categories of a digital asset:

- 1st category: criteria No. $1 ; 2 ; 3 ; 4$;

- 2nd category: criteria No. 5; 6;

- 3rd category: criteria No. 7; 8;

- 4th category: criterion No. 9;

3) two questions correspond to each criterion, the answers to these questions allow determining whether a blockchain token has an indicator, which in turn, allows determining whether certain characteristics of a blockchain token correspond to this criterion;

4) assignment of criteria of equal importance to each of the categories. 
Thus, the degree of compliance of the characteristics of a blockchain token with each category is a necessary condition for determining the degree of correspondence of a blockchain token to a digital asset.

Let us consider the criteria in detail.

1. Uniqueness. This criterion indicates the uniqueness of a blockchain token and is characterized by the following indicator: the existence of a document that records the issue date of a blockchain token and determines the number of a blockchain token.

2. Identifiability. This criterion points out the creator of the document and is characterized by the following indicators: the existence of an indication of a blockchain token's creator in the document; the ability to confirm the legal claim of the creator of a blockchain token in relation to a value.

3. Regulability. This criterion indicates that the process for implementing legal claim with respect to a blockchain token is regulated and is characterized by the following indicator: the existence of a document that establishes the rules and conditions for using a blockchain token.

4. Sessionality. This criterion is determined by the period during which a blockchain token exists and is characterized by the following indicator: the existence of a document that sets the circulation period of a blockchain token and determines an event that affects the validity of the blockchain token.

5. Derivativeness. This criterion indicates the nature of a blockchain token derivative of the right to a value and is revealed through the following indicator: whether a blockchain token provides its holder with access to the complex of rights and obligations of the owner of value; whether a blockchain token provides its owner with the right to demand the fulfillment of a set of rights and obligations.

6. Verifiability. This criterion indicates the existence of reliable evidence of the owner's property rights to the value and is characterized by the following indicators: the existence of a document that contains information that reliably indicates the owner's property right to the value, from which the blockchain token derives; the existence of a document that contains reliable information about the 
scope of the rights of the value's owner and third parties to the value, from which the blockchain token derives.

7. Transparency. This criterion indicates the possibility of analyzing the history of transactions with a blockchain token based on existing accounting methods and is characterized by the following indicators: whether information on the parties to the transaction is displayed in the history of transactions with a blockchain token; transaction accounting is based on previous transactions (UTXO) or on the balance accounting of a blockchain token.

8. Decentralization. This criterion indicates the independence of the environment, in which the blockchain token circulates, from centralized decision-making and is characterized by the following indicators: the existence of documented mechanisms for management and development of the blockchain token circulation environment by the community; maintenance of the infrastructure of the blockchain token circulation environment by the community.

9. Accountability. This criterion indicates the recording of the transfer of a certain number of blockchain tokens from one identified party to another and is characterized by the following indicators: the ability to account the transfer of the number of blockchain tokens between identified parties in a transaction; the ability to record the actions of the parties through a transaction identifier.

It should be noted that today the given number of criteria is optimal and sufficient to obtain reliable indicators for determining the characteristics of a blockchain token as a digital asset in order to comply with existing international legal standards. 


\section{SECTION 2 \\ ORGANIZING AND CONDUCTING THE RESEARCH OF CHARACTERISTICS OF A BLOCKCHAIN TOKEN}

\subsection{Research of Characteristics of a Blockchain Token}

Blockchain tokens can be studied using various methods: from a simple observation of its exchange value to complex mathematical calculations and construction of theoretical models.

The research of characteristics of any blockchain token implies the use of a special questionnaire developed by us, which does not require extensive knowledge in the field of information and/or digital economy and can be completed both individually and collectively. To conduct the research, the respondent needs to fill in a special form with a list of questions. After completing the research, i.e. after filling in all the required fields, the respondent gets an opportunity to analyze the obtained results using Table 2 .

The questionnaire has been developed according to specific criteria and indicators of a blockchain token, it contains 18 questions, the answers to which allow specifying the characteristics of a blockchain token. The respondent must choose only one out of three answers (A, B, C), which are graded in accordance with the scale in Table 2.

The information gathered using this methodology allows determining how much a blockchain token corresponds to a digital asset and also characterizing a blockchain token as:

- unique/non-unique;

- identifiable/non-identifiable;

- regulated/non-regulated;

- sessional/non-sessional;

- derivative/non-derivative;

- verifiable/non-verifiable;

- transparent/non-transparent;

- decentralized/centralized;

- accountable/non-accountable. 
In order to get the most precise results, the questions are arranged in a way that they specify every criterion twice. The analysis of the correspondence of answers to each criterion allows gathering information about the randomness of answers and/or mistakes.

\section{QUESTIONNAIRE}

Instruction: "You have an opportunity to diagnose a blockchain token (hereinafter referred to as "BT"). In order to do that, you need to answer 18 questions, which characterize it. In a special form, fill in the information about yourself and answer every question by choosing one of the proposed answers: A - Yes; B - Don't know; C - No.

Write the selected answer next to each question in a special column made for that purpose. There is no time limit for answering".

Date $\quad \overline{\text { Surname and initials }} \quad$ Higher education degree

Specialty

Work experience (years)

Table 2

Questions for Testing the Characteristics of a Blockchain Token

\begin{tabular}{|c|l|l|}
\hline No. & \multicolumn{1}{|c|}{ Question } & Answer \\
\hline 1. & $\begin{array}{l}\text { Is there a document that registers the issue date } \\
\text { of the BT? }\end{array}$ & \\
\hline 2. & $\begin{array}{l}\text { Is the creator of the BT specified directly in the } \\
\text { document? }\end{array}$ & \\
\hline 3. & $\begin{array}{l}\text { Is there a document that establishes the terms of } \\
\text { using the BT? }\end{array}$ & \\
\hline 4. & $\begin{array}{l}\text { Is there a document that sets the BT's } \\
\text { circulation period? }\end{array}$ & \\
\hline 5. & $\begin{array}{l}\text { Does the BT provide its owner with access to a } \\
\text { set of rights and obligations of the value's } \\
\text { owner? }\end{array}$ & \\
\hline
\end{tabular}




\begin{tabular}{|c|c|c|}
\hline No. & Question & Answer \\
\hline 6. & $\begin{array}{l}\text { Is there a document that contains information, } \\
\text { which reliably specifies the owner's property } \\
\text { right to the value, which the BT derives from? }\end{array}$ & \\
\hline 7. & $\begin{array}{l}\text { Does the BT transaction history display } \\
\text { information about the parties involved in the } \\
\text { transaction? }\end{array}$ & \\
\hline 8. & $\begin{array}{l}\text { Are there recorded mechanisms of management } \\
\text { and development of the BT's circulation } \\
\text { environment for the community? }\end{array}$ & \\
\hline 9. & $\begin{array}{l}\text { Is the accounting of the BT transfer amount } \\
\text { between the identified parties of the transaction } \\
\text { possible? }\end{array}$ & \\
\hline 10. & $\begin{array}{l}\text { Is there a document that determines the number } \\
\text { of BTs? }\end{array}$ & \\
\hline 11. & $\begin{array}{l}\text { Does the document allow confirming the legal } \\
\text { claim of the creator of the BT to the value? }\end{array}$ & \\
\hline 12. & $\begin{array}{l}\text { Is there a document that establishes the } \\
\text { conditions for using the BT? }\end{array}$ & \\
\hline 13. & $\begin{array}{l}\text { Is there a document that determines an event, } \\
\text { which affects the validity period of the BT? }\end{array}$ & \\
\hline 14. & $\begin{array}{l}\text { Does the BT provide its owner with the right to } \\
\text { demand the fulfillment of a set of rights and } \\
\text { obligations from the owner of the value? }\end{array}$ & \\
\hline 15. & $\begin{array}{l}\text { Is there a document that contains reliable } \\
\text { information about the scope of the rights of the } \\
\text { value's owner and third parties to the value, } \\
\text { which the BT derives from? }\end{array}$ & \\
\hline 16. & $\begin{array}{l}\text { Is the accounting of transactions conducted } \\
\text { based on the previous transactions (UTXO) or } \\
\text { on the balance accounting of the BT? }\end{array}$ & \\
\hline 17. & $\begin{array}{l}\text { Does the community support the infrastructure } \\
\text { of the BT's circulation environment? }\end{array}$ & \\
\hline 18. & $\begin{array}{l}\text { Is it possible to record the actions of the } \\
\text { identified parties by using the transaction } \\
\text { identifier BT? }\end{array}$ & \\
\hline
\end{tabular}




\subsection{Analysis of Research Results}

The questionnaire results are evaluated using Table 3. 0 points.

The maximum total number of points is: 16 points, minimum:

This table is based on one of the aspects of the principle of equivalence of categories, which means that each criterion has two questions similar in their nature.

Table 3

\section{Formation of Test Results}

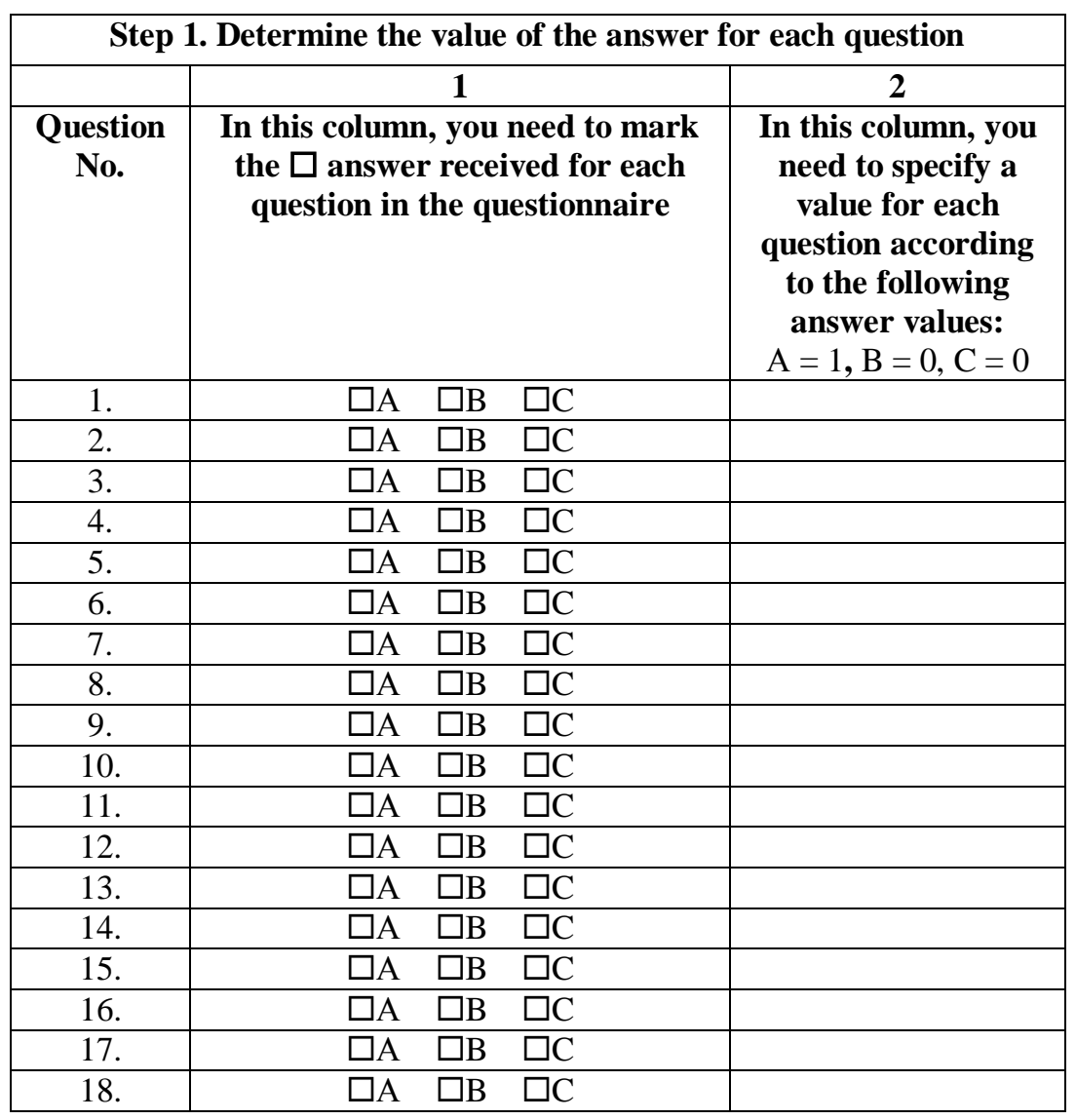




\begin{tabular}{|c|c|c|c|c|}
\hline \multicolumn{5}{|c|}{ Step 2. Determine the values } \\
\hline \multirow[b]{2}{*}{$\begin{array}{c}\text { Criterion } \\
\text { No. }\end{array}$} & 1 & 2 & 3 & 4 \\
\hline & Criterion & $\begin{array}{l}\text { Numbers } \\
\text { of the } \\
\text { two } \\
\text { questions } \\
\text { corres- } \\
\text { ponding } \\
\text { to each } \\
\text { criterion }\end{array}$ & $\begin{array}{c}\text { Enter } \\
\text { the } \\
\text { values } \\
\text { from } \\
\text { column } 2 \\
\text { of Step } 1 \\
\text { into the } \\
\text { cell } \\
\text { corres- } \\
\text { ponding } \\
\text { to each } \\
\text { question }\end{array}$ & $\begin{array}{l}\text { In this column, } \\
\text { you need to } \\
\text { specify the value } \\
\text { obtained } \\
\text { through simple } \\
\text { multiplication of } \\
\text { the two values of } \\
\text { answers } \\
\text { corresponding } \\
\text { to each criterion } \\
\text { in column } 3 \\
\text { of Step } 2\end{array}$ \\
\hline \multirow{2}{*}{1.} & \multirow{2}{*}{$\begin{array}{l}\text { Unique- } \\
\text { ness }\end{array}$} & 1 & & \\
\hline & & 10 & & \\
\hline \multirow{2}{*}{2.} & \multirow{2}{*}{$\begin{array}{l}\text { Identifi- } \\
\text { ability }\end{array}$} & 2 & & \\
\hline & & 11 & & \\
\hline \multirow{2}{*}{3.} & \multirow{2}{*}{$\begin{array}{l}\text { Regul- } \\
\text { ability }\end{array}$} & 3 & & \\
\hline & & 12 & & \\
\hline \multirow{2}{*}{4.} & \multirow{2}{*}{$\begin{array}{l}\text { Session- } \\
\text { ality }\end{array}$} & 4 & & \\
\hline & & 13 & & \\
\hline \multirow{2}{*}{5.} & \multirow{2}{*}{$\begin{array}{l}\text { Deriva- } \\
\text { tiveness }\end{array}$} & 5 & & \\
\hline & & 14 & & \\
\hline \multirow{2}{*}{6.} & \multirow{2}{*}{$\begin{array}{l}\text { Verifi- } \\
\text { ability }\end{array}$} & 6 & & \\
\hline & & 15 & & \\
\hline \multirow{2}{*}{7.} & \multirow{2}{*}{$\begin{array}{l}\text { Trans- } \\
\text { parency }\end{array}$} & 7 & & \\
\hline & & 16 & & \\
\hline \multirow{2}{*}{8.} & \multirow{2}{*}{$\begin{array}{l}\text { Decentra- } \\
\text { lization }\end{array}$} & 8 & & \\
\hline & & 17 & & \\
\hline \multirow{2}{*}{9.} & \multirow{2}{*}{$\begin{array}{l}\text { Account- } \\
\text { ability }\end{array}$} & 9 & & \\
\hline & & 18 & & \\
\hline
\end{tabular}




\begin{tabular}{|c|c|c|c|}
\hline \multicolumn{4}{|c|}{$\begin{array}{c}\text { Step 3. Determine whether the results obtained in the } \\
\text { questionnaire correspond to the criteria of a digital asset }\end{array}$} \\
\hline \multirow{2}{*}{ No. } & $\mathbf{1}$ & $\mathbf{2}$ & $\mathbf{3}$ \\
\cline { 2 - 4 } & $\begin{array}{c}\text { Enter the } \\
\text { values from } \\
\text { column 4 of } \\
\text { Step into the } \\
\text { column }\end{array}$ & Action & $\begin{array}{c}\text { In this column, write } \\
\text { down the result after } \\
\text { completing a simple } \\
\text { multiplication of values } \\
\text { specified in columns 1 } \\
\text { and 2 of Step 3 }\end{array}$ \\
\hline 1. & & $\times 1$ & \\
\hline 2. & & $\times 1$ & \\
\hline 3. & & $\times 1$ & \\
\hline 4. & & $\times 2$ & \\
\hline 5. & & $\times 2$ & \\
\hline 6. & & $\times 2$ & \\
\hline 7. & & $\times 4$ & \\
\hline 8. & & & \\
\hline 9. & & & \\
\hline
\end{tabular}

Now you simply need to add the values in column 3 of Step 3, and the obtained result will be the total number of points that you can use to interpret the results of the research in accordance with Table 4.

Points in total: 


\subsection{Interpretation of Research Results}

Whether the characteristics of a blockchain token correspond to those of a digital asset can be determined based on the normal distribution of indicators presented in Table 4.

Table 4

Grade Scale of the Indicators of a Blockchain Token

\begin{tabular}{|c|c|}
\hline Range, points & Results \\
\hline $1-8$ & $\begin{array}{l}\text { BT does not correspond to a digital asset, i.e. } \\
\text { it is not a digital asset. } \\
\text { The obtained result reliably confirms the } \\
\text { absence of the required level of correspondence } \\
\text { of a blockchain token to a digital asset }\end{array}$ \\
\hline 9-12 & $\begin{array}{l}\text { BT can theoretically be a digital asset, but in } \\
\text { reality, it is not one. } \\
\text { This conditionally negative result is based on the } \\
\text { fact that the characteristics of a blockchain token } \\
\text { can correspond to all four categories of a digital } \\
\text { asset, but the obtained number of points is not } \\
\text { sufficient to get reliable indicators in order to } \\
\text { define a BT as a digital asset }\end{array}$ \\
\hline 13-16 & $\begin{array}{l}\text { BT corresponds to a digital asset, i.e. it is a } \\
\text { digital asset. } \\
\text { This result indicates the required level of } \\
\text { correspondence of a blockchain token to a digital } \\
\text { asset, which means it is a digital asset }\end{array}$ \\
\hline
\end{tabular}




\section{SECTION 3 \\ MATHEMATICAL FORMALIZATION \\ OF METHODOLOGY FOR DIAGNOSING WHETHER \\ CHARACTERISTICS OF A BLOCKCHAIN TOKEN \\ CORRESPOND TO THOSE OF A DIGITAL ASSET}

3.1. Triple Classification Based on the Results of the Diagnostics on Whether a Blockchain Token Corresponds to a Digital Asset

The questionnaire of this methodology contains 18 questions numbered from 1 to 18 , which we will denote as $b(1), b(2), \ldots, b(18)$. Each question has three possible answers: "Yes", "No", "Don't know". The answer to $i$-th question forms a numeric value a(i)

$$
\begin{aligned}
& a(i)=\{1 \text { if the answer to } i \text {-th question is "Yes"; } \\
& 0 \text { if the answer to } i \text {-th question is "No"; } \\
& 0 \text { if the answer to i-th question is "Don't know", } \\
& \mathrm{i}=1,2, \ldots, 18 \text {. }
\end{aligned}
$$

Depending on the answers to the posed questions, the sum $\mathrm{C}$, which consists of 9 summands,

$$
\mathrm{C}=\mathrm{X}(1)+\mathrm{X}(2)+\ldots+\mathrm{X}(9)
$$

is formed as follows:

$$
\begin{aligned}
& \mathrm{X}(1)=\mathrm{a}(1) \mathrm{a}(10), \\
& \mathrm{X}(2)=\mathrm{a}(2) \mathrm{a}(11), \\
& \mathrm{X}(3)=\mathrm{a}(3) \mathrm{a}(12), \\
& \mathrm{X}(4)=\mathrm{a}(4) \mathrm{a}(13), \\
& \mathrm{X}(5)=2 \mathrm{a}(5) \mathrm{a}(14), \\
& \mathrm{X}(6)=2 \mathrm{a}(6) \mathrm{a}(15), \\
& X(7)=2 \mathrm{a}(7) \mathrm{a}(16), \\
& X(8)=2 \mathrm{a}(8) \mathrm{a}(17), \\
& X(9)=4 \mathrm{a}(9) \mathrm{a}(18)
\end{aligned}
$$

Based on the test results, the blockchain token can be assigned to one of three classes. 


\section{Class 1}

BT does not correspond to a digital asset, i.e. it is not a digital asset if the sum $\mathrm{C}$ formed as a result of answering the questions is less than or equal to 8

$$
\mathrm{BT}=\mathrm{NDA} \text { if } \mathrm{C} \leq 8 .
$$

\section{Class 2}

BT can theoretically be a digital asset, but in reality, it is not one if the sum C formed as a result of answering the questions is between 9 and 12

$$
\mathrm{BT}=\mathrm{NDA} \text { if } 9 \leq \mathrm{C} \leq 12 .
$$

In this case, it is assumed that the blockchain token can potentially become a digital asset, i.e. it corresponds to the boundaries of a digital asset, but technically is not one at the time of testing.

\section{Class 3}

BT corresponds to a digital asset, i.e. it is a digital asset if the sum $\mathrm{C}$ formed as a result of answering the questions is more than or equal to 13

$$
\mathrm{BT} \in \mathrm{DA} \text { if } \mathrm{C} \geq 13 \text {. }
$$

As a result of this triple classification, an understanding of the boundaries of digital assets appears, which has a positive Jordan measure (length of the interval $[9 ; 12]$ equals $3>0$ ). 
3.2. Reliability of the Methodology for Diagnosing the Blockchain Token Based on the Number of Points Received

If the number of points received for answering 18 questions is $\mathrm{c}$, then we need to find the probability

$$
\Delta=\mathrm{P}(\mathrm{C} \geq \mathrm{c})
$$

that the total sum will be no less than $\mathrm{c}\{\mathrm{C} \geq \mathrm{c}\}$ with randomly selected answers \{"Yes", "No", "Don't know"\} to each of the 18 questions. Then we determine the reliability $\mathrm{P}$ of the obtained result of the diagnostic methodology using the formula

$$
\mathrm{P}=1-\delta=1-\mathrm{P}(\mathrm{C} \geq \mathrm{c}) \text {. }
$$

\section{Probability Structure of the Resulting Sum C with Randomly Selected Answers}

To determine the sought probability, let us study the probability structure of the sum C

$$
\mathrm{C}=\mathrm{X}(1)+\mathrm{X}(2)+\ldots+\mathrm{X}(9)
$$

where

$$
\begin{aligned}
& \mathrm{X}(1)=\mathrm{a}(1) \mathrm{a}(10), \\
& \mathrm{X}(2)=\mathrm{a}(2) \mathrm{a}(11), \\
& \mathrm{X}(3)=\mathrm{a}(3) \mathrm{a}(12), \\
& \mathrm{X}(4)=\mathrm{a}(4) \mathrm{a}(13), \\
& \mathrm{X}(5)=2 \mathrm{a}(5) \mathrm{a}(14), \\
& \mathrm{X}(6)=2 \mathrm{a}(6) \mathrm{a}(15), \\
& \mathrm{X}(7)=2 \mathrm{a}(7) \mathrm{a}(16), \\
& \mathrm{X}(8)=2 \mathrm{a}(8) \mathrm{a}(17), \\
& \mathrm{X}(9)=4 \mathrm{a}(9) \mathrm{a}(18),
\end{aligned}
$$

assuming that $\mathrm{a}(1), \mathrm{a}(2), \ldots, \mathrm{a}(18)$ form a set of independent and identically distributed random variables with a random distribution a that can have only two values: 1 with the probability of $1 / 3$,

$$
\mathrm{P}(\mathrm{a}=1)=1 / 3,
$$

and 0 with the probability of $2 / 3$,

$$
\mathrm{P}(\mathrm{a}=0)=23 \text {. }
$$


Technically, this distribution is the Bernoulli distribution for the number of successful outcomes in one test with the probability of success of $1 / 3$ (in case the answer to the question is "Yes").

In this assumption, random variables $\{X(k), k=1,2, \ldots, 9\}$ are independent when combined and the first four, i.e. $X(1), X(2), X(3)$, $\mathrm{X}(4)$, have the same Bernoulli distribution as the random variable $\mathrm{X}$ : $\mathrm{p}=\mathrm{P}(\mathrm{X}=1)=1 / 9$ and $\mathrm{q}=\mathrm{P}(\mathrm{X}=0)=1-\mathrm{p}=89$. In our assumptions, for any $\mathrm{i} \neq \mathrm{j}$ (can be viewed as $1 \leq \mathrm{i}<\mathrm{j} \leq 18$ ) the product of variables $\mathrm{a}(\mathrm{i})$ and $\mathrm{a}(\mathrm{j})$, each being equal to either 0 or 1 , can also have only two values -0 or 1 and

$$
\begin{aligned}
& \mathrm{P}[\mathrm{a}(\mathrm{i}) \mathrm{a}(\mathrm{j})=1]=\mathrm{P}[\mathrm{a}(\mathrm{i})=1] \mathrm{P}[\mathrm{a}(\mathrm{j})=1]=(1 / 3)(1 / 3)=1 / 9, \\
& \mathrm{P}[\mathrm{a}(\mathrm{i}) \mathrm{a}(\mathrm{j})=0]=1-\mathrm{P}[\mathrm{a}(\mathrm{i}) \mathrm{a}(\mathrm{j})=1]=1-1 / 9=89 .
\end{aligned}
$$

The total sum of the received points can be written down as the sum of four summands

$$
\mathrm{C}=\mathrm{C}(1)+\mathrm{C}(2)+\mathrm{C}(3)+\mathrm{C}(4),
$$

of the points received in the four corresponding categories

$$
\begin{gathered}
\mathrm{C}(1)=\mathrm{X}(1)+\mathrm{X}(2)+\mathrm{X}(3)+\mathrm{X}(4) \\
\mathrm{C}(2)=\mathrm{X}(5)+\mathrm{X}(6) \\
\mathrm{C}(3)=\mathrm{X}(7)+\mathrm{X}(8) \\
\mathrm{C}(3)=\mathrm{X}(9)
\end{gathered}
$$

For the first category, the sum of the received points

$$
\mathrm{C}(1)=\mathrm{X}(1)+\mathrm{X}(2)+\mathrm{X}(3)+\mathrm{X}(4)
$$

represents the number of successful outcomes in four independent tests with the probability of success of 1/9 (positive answer to two grouped questions) in each separate test and has a binomial distribution (Bernoulli formula)

$$
\mathrm{P}[\mathrm{C}(1)=\mathrm{k}]=(\mathrm{n} !([\mathrm{k} !(\mathrm{n}-\mathrm{k}) !]))\left(\mathrm{p}^{\wedge} \mathrm{k}\right)\left(\mathrm{q}^{\wedge}(\mathrm{n}-\mathrm{k})\right), \mathrm{k}=0,1,2, \ldots, \mathrm{n},
$$

for the number of successful outcomes in a series of four $(\mathrm{n}=$ 4) independent tests with the probability of success $p=1 / 9$ in each separate test and the probability of failure $\mathrm{q}=89$.

Example 1. Let us find the probability $\mathrm{P}[\mathrm{C}(1) \geq 1]$ that the total number of points received in the first category is not less than one. It equals

$$
\mathrm{P}[\mathrm{C}(1) \geq 1]=1-\mathrm{P}[\mathrm{C}(1)=0]=1-\mathrm{q}^{\wedge} \mathrm{n}
$$


and after substituting the values $\mathrm{n}=4, \mathrm{q}=89$ $\mathrm{P}[\mathrm{C}(1) \geq 1]=1-\mathrm{P}[\mathrm{C}(1)=0]=1-(89)^{\wedge} 4=2465 / 6561=0,3757 \ldots$.

Example 2. Let us assume that $\mathrm{n}=4, \mathrm{p}=19$. Now let us find the probability $\mathrm{P}[\mathrm{C}(1) \geq 3]$ that the total number of points received in the first category is not less than three. This probability can be represented as a sum of two summands, the probability $\mathrm{P}[\mathrm{C}(1)=3]$ of getting 3 points in this category and the probability $\mathrm{P}[\mathrm{C}(1)=4]$ of getting 4 points in the first category. Both probabilities are calculated using the Bernoulli formula for binomial distribution

$$
\begin{aligned}
& \mathrm{P}[\mathrm{C}(1)=3]=4\left((1 / 9)^{\wedge} 3\right)(89), \\
& \mathrm{P}[\mathrm{C}(1)=4]=(1 / 9)^{\wedge} 4,
\end{aligned}
$$

which helps us to determine the sought probability

$\mathrm{P}[\mathrm{C}(1) \geq 3]=\mathrm{P}[\mathrm{C}(1)=3]+\mathrm{P}[\mathrm{C}(1)=4]=4\left((1 / 9)^{\wedge} 3\right)(89)+$ $(1 / 9)^{\wedge} 4=33 / 9^{\wedge} 4=33 / 6561=0,005 \ldots$.

For the second category, the sum of the received points

$$
\mathrm{C}(2)=\mathrm{X}(5)+\mathrm{X}(6)
$$

represents the doubled number of successful outcomes in two independent tests with the probability of success of 1/9 (positive answer to two grouped questions for the fifth and sixth criteria) in each separate test and has the distribution of the random variable that has the values 0,2 and 4 with probabilities

$$
\begin{aligned}
& \mathrm{P}[\mathrm{C}(2)=0]=(89)^{\wedge} 2=0,79012 \ldots, \\
& \mathrm{P}[\mathrm{C}(2)=2]=2(1 / 9)(89)=0,19753 \ldots, \\
& \mathrm{P}[\mathrm{C}(2)=4]=(1 / 9)^{\wedge} 2=0,01234 \ldots .
\end{aligned}
$$

Similarly, for the third category, the sum of the received points

$$
\mathrm{C}(3)=\mathrm{X}(7)+\mathrm{X}(8)
$$

represents the doubled number of successful outcomes in two independent tests with the probability of success of 1/9 (positive answer to two grouped questions for the seventh and eighth criteria) in each separate test and has the distribution of the random variable that has the values 0,2 and 4 with probabilities

$$
\begin{aligned}
& \mathrm{P}[\mathrm{C}(3)=0]=(89)^{\wedge} 2=0,79012 \ldots, \\
& \mathrm{P}[\mathrm{C}(3)=2]=2(1 / 9)(89)=0,19753 \ldots, \\
& \mathrm{P}[\mathrm{C}(3)=4]=(1 / 9)^{\wedge} 2=0,01234 \ldots .
\end{aligned}
$$


For the fourth category, the number of the received points

$$
\mathrm{C}(4)=\mathrm{X}(9)=4 \mathrm{a}(9) \mathrm{a}(18)
$$

represents the number of successful outcomes multiplied by four in one test with the probability of success of 1/9 (positive answer to two grouped questions for the ninth criterion) in this test and has the distribution of the random variable that has the values 0 or 4 with probabilities

$$
\begin{aligned}
& \mathrm{P}[\mathrm{C}(4)=0]=89 \\
& \mathrm{P}[\mathrm{C}(4)=4]=1 / 9 .
\end{aligned}
$$

\section{The probability of getting at least 13 points in sum C}

Let us find the exact probability value $\mathrm{P}[\mathrm{C} \geq 13]$ in the assumption of an equally possible selection of answers (randomly chosen answers) to all 18 questions out of three possible answers \{"Yes", "No", "Don't know"\}. Thus, we have

$$
\mathrm{C}=\mathrm{C}(1)+\mathrm{C}(2)+\mathrm{C}(3)+\mathrm{C}(4)
$$

the total number of points that is the sum of the points received in all four categories. Meanwhile, the maximum number of points for each category equals:

$$
\max [\mathrm{C}(\mathrm{k}), \mathrm{k}=1,2,3,4]=4 .
$$

As a result, the maximum possible total number of points $\mathrm{C}^{\wedge}(\max )$ is sixteen

$$
\mathrm{C}^{\wedge}(\max )=\max [\mathrm{C}(1)+\mathrm{C}(2)+\mathrm{C}(3)+\mathrm{C}(4)]=4+4+4+4=16 \text {. }
$$

Based on that and the content of a set of integers

$$
\mathrm{C}(1)=\{0 ; 1 ; 2 ; 3 ; 4\}, \mathrm{C}(2)=\{0 ; 2 ; 4\}, \mathrm{C}(3)=\{0 ; 2 ; 4\}, \mathrm{C}(4)
$$
$=\{0 ; 4\}$,

13 points or more in total

$$
\mathrm{C}=\mathrm{C}(1)+\mathrm{C}(2)+\mathrm{C}(3)+\mathrm{C}(4)
$$

can be received only if $\mathrm{C}(4)=4$ (for $\mathrm{C}(4)=0$ total sum $\mathrm{C} \leq 16$ $-4=12<13$ less than thirteen). If $\mathrm{C}(4)=4$, then the random event $\{\mathrm{C}$ $\geq 13\}$ is represented as a sum of mutually exclusive random events (for sum $\mathrm{C}$ not less than 13 only the following options are possible):

$$
\begin{aligned}
& \mathrm{A}=\{\mathrm{C}(4)=4, \mathrm{C}(3)=4, \mathrm{C}(2)=4, \mathrm{C}(1) \geq 1\}, \\
& \mathrm{B}=\{\mathrm{C}(4)=4, \mathrm{C}(3)=4, \mathrm{C}(2)=2, \mathrm{C}(1) \geq 3\}, \\
& \mathrm{D}=\{\mathrm{C}(4)=4, \mathrm{C}(3)=2, \mathrm{C}(2)=4, \mathrm{C}(1) \geq 3\} .
\end{aligned}
$$


Due to the independence of random variables $\{\mathrm{C}(1), \mathrm{C}(2), \mathrm{C}(3)$, $\mathrm{C}(4)\}$, the probability of each of these three events is calculated as a product of probabilities of events related to each of these variables. Meanwhile, we will need the following probabilities calculated previously as multipliers:

$$
\begin{aligned}
& \mathrm{P}[\mathrm{C}(4)=4]=1 / 9, \\
& \mathrm{P}[\mathrm{C}(3)=4]=(1 / 9)^{\wedge} 2=1 / 81, \\
& \mathrm{P}[\mathrm{C}(2)=4]=(1 / 9)^{\wedge} 2=1 / 81 \\
& \mathrm{P}[\mathrm{C}(1) \geq 1]=\left(\left(9^{\wedge} 4-8^{\wedge} 4\right)\right) 9^{\wedge} 4=2465 / 6561, \\
& \mathrm{P}[\mathrm{C}(2)=2]=2(1 / 9)(89)=1681 \\
& \mathrm{P}[\mathrm{C}(3)=2]=2(1 / 9)(89)=1681 \\
& \mathrm{P}[\mathrm{C}(1) \geq 3]=4\left((1 / 9)^{\wedge} 3\right)(8 / 9)+(1 / 9)^{\wedge} 4=33 / 9^{\wedge} 4=33 / 6561 .
\end{aligned}
$$

Thus,

$$
\mathrm{P}[\mathrm{C}(4)=4, \mathrm{C}(3)=4, \mathrm{C}(2)=4, \mathrm{C}(1) \geq 1]=\mathrm{P}[\mathrm{C}(4)=4] \mathrm{P}[\mathrm{C}(3)=
$$
4] $\mathrm{P}[\mathrm{C}(2)=4] \mathrm{P}[\mathrm{C}(1) \geq 1]$

above

After substituting the values of the probabilities calculated

$$
\begin{aligned}
& \mathrm{P}[\mathrm{C}(4)=4, \mathrm{C}(3)=4, \mathrm{C}(2)=4, \mathrm{C}(1) \geq 1]= \\
& \left.(1 / 9)\left((1 / 9)^{\wedge} 2\right)\left((1 / 9)^{\wedge} 2\right)\left[\left(\left(9^{\wedge} 4-8^{\wedge} 4\right)\right)\right)^{\wedge} 4\right]=\left(\left(9^{\wedge} 4-8^{\wedge} 4\right)\right) 9^{\wedge} 9, \\
& \text { or } \\
& \mathrm{P}[\mathrm{C}(4)=4, \mathrm{C}(3)=4, \mathrm{C}(2)=4, \mathrm{C}(1) \geq 1]=\left(\left(9^{\wedge} 4-8^{\wedge} 4\right)\right) 9^{\wedge} 9= \\
& 2465 / 387420489 .
\end{aligned}
$$

Then

$$
\mathrm{P}[\mathrm{C}(4)=4, \mathrm{C}(3)=4, \mathrm{C}(2)=2, \mathrm{C}(1) \geq 3]=\mathrm{P}[\mathrm{C}(4)=4] \mathrm{P}[\mathrm{C}(3)=
$$
$4] \mathrm{P}[\mathrm{C}(2)=2] \mathrm{P}[\mathrm{C}(1) \geq 3]$

above

After substituting the values of the probabilities calculated

$\mathrm{P}[\mathrm{C}(4)=4, \mathrm{C}(3)=4, \mathrm{C}(2)=2, \mathrm{C}(1) \geq 3]=$ $(1 / 9)\left((1 / 9)^{\wedge} 2\right)\left(169^{\wedge} 2\right)\left(33 / 9^{\wedge} 4\right)=5289^{\wedge} 9$,

or

$\mathrm{P}[\mathrm{C}(4)=4, \mathrm{C}(3)=4, \mathrm{C}(2)=2, \mathrm{C}(1) \geq 3]=5289^{\wedge} 9=$ 528387420489 .

And finally,

$\mathrm{P}[\mathrm{C}(4)=4, \mathrm{C}(3)=2, \mathrm{C}(2)=4, \mathrm{C}(1) \geq 3]=\mathrm{P}[\mathrm{C}(4)=4] \mathrm{P}[\mathrm{C}(3)=$ $2] \mathrm{P}[\mathrm{C}(2)=4] \mathrm{P}[\mathrm{C}(1) \geq 3]$ 


\section{above}

After substituting the values of the probabilities calculated

$$
\begin{aligned}
& \mathrm{P}[\mathrm{C}(4)=4, \mathrm{C}(3)=2, \mathrm{C}(2)=4, \mathrm{C}(1) \geq 3]= \\
& (1 / 9)\left(169^{\wedge} 2\right)\left((1 / 9)^{\wedge} 2\right)\left(33 / 9^{\wedge} 4\right)=5289^{\wedge} 9, \\
& \text { or } \\
& \mathrm{P}[\mathrm{C}(4)=4, \mathrm{C}(3)=2, \mathrm{C}(2)=4, \mathrm{C}(1) \geq 3]=5289^{\wedge} 9= \\
& 528387420489 .
\end{aligned}
$$

Due to the third axiom of probability theory, the sought probability $\mathrm{P}[\mathrm{C} \geq 13]$ can be calculated as a sum of probabilities of three mutually exclusive events

$$
\begin{aligned}
& \mathrm{P}[\mathrm{C} \geq 13]=\mathrm{P}(\mathrm{A})+\mathrm{P}(\mathrm{B})+\mathrm{P}(\mathrm{D})=2465 / 9^{\wedge} 9+5289^{\wedge} 9+5289^{\wedge} 9 \\
& =3521 / 387420489, \\
& \text { or the sought probability equals } \\
& \delta=\mathrm{P}[\mathrm{C} \geq 13]=3521 / 387420489=9,0883 \ldots / 10^{\wedge} 6<1 / 10^{\wedge} 5 \\
& \text { Thus, a precise evaluation of reliability of the results of }
\end{aligned}
$$
diagnosing whether a blockchain token corresponds to a digital asset is

$$
\underline{P}=1-P[C \geq 13]=1-3521 / 387420489=
$$
$\underline{387416968387420489=0,9999909 \ldots . .>0,99999}$.

Thus, the reliability of this methodology for diagnosing whether a blockchain token corresponds to a digital asset is more than 0.99999. This means that the probability that randomly selected answers to 18 questions using this methodology will result in a positive outcome of diagnosing whether a blockchain token corresponds to a digital asset is less than $1 / 10^{\wedge} 5$.

Based on the above-mentioned information, we can state the actual mathematical justification of the methodology for diagnosing whether a blockchain token corresponds to a digital asset. This methodology, with overwhelming (close to unity) probability, allows answering the question: is this specific blockchain token a digital asset or not? If the number of points received as a result of answering 18 questions and calculated using this methodology is more than or equal to thirteen $\mathrm{C} \geq 13$, the diagnosed blockchain token corresponds to a digital asset, i.e. it is a digital asset. 
If the received sum is $\mathrm{C}<13$, then the blockchain token does not correspond to a digital asset, i.e. it is not a digital asset. However, in this set of sums $\{C \leq 12\}$, there is a subset $\{9 \leq \mathrm{C} \leq 12\}$, and if the test results of the characteristics of a blockchain token are within this subset, then this token can theoretically be a digital asset, but technically it is not one and is more likely to correspond to the boundaries of a digital asset. It is the so-called boundary set of conditions (not corresponding to digital assets), but contributing to the transition of the blockchain token to class 3 - into the multitude of digital assets (conditionally negative result). And definitely negative result when the sum is $\mathrm{C} \leq 8$. This is the essence of the triple classification (division into three sets of integer values) of a numerical display of answers to 18 questions using this methodology:

$$
0 \leq \mathrm{C} \leq 8 \text { - definitely no, not a DA; }
$$

$9 \leq \mathrm{C} \leq 12-$ no, but there is a possibility of transition to a DA;

$$
\mathrm{C} \geq 13 \text { - yes, DA. }
$$




\section{CONCLUSIONS}

Using modern theoretical, methodological and mathematical foundations to study the issue of researching a blockchain token in order to determine the level of its correspondence to a digital asset allowed reaching the following conclusions.

1. The analysis of literature sources allowed researching the following terms: "blockchain token", "digital currency", "virtual currency", "cryptocurrency", "digital asset", "virtual asset", "cryptoasset", "digital money", "virtual money", "electronic money" and others. The theoretical analysis of scientific literature indicates that, in modern economic science and practice, the essence and nature of digital assets have not been fully recognized and accepted by modern society due to the high pace of development of new forms of presenting digital technologies and a significant delay in forming the corresponding theoretical basis and concrete conceptual and categorical apparatus. Meanwhile, the most substantiated in the economic and legal aspects and, therefore, correct present-day definition is "Digital asset is an information resource derivative of the right to a value and circulating in the distributed ledger in the form of a unique identifier".

2. The features of the main terms of the research, for example, the term "digital asset" and four structural components in its definition, as well as the development of the digital and information economy in the international legal field, allowed establishing:

- four categories to objectively determine whether a blockchain token corresponds to a digital asset;

- sufficiency of criteria due to the differentiation of 9 criteria of a digital asset into four categories depending on the correspondence of the criteria to the categories of a digital asset;

- indicators of the blockchain token's characterization as a digital asset, in particular: uniqueness, identifiability, regulability, sessionality, derivativeness, verifiability, transparency, decentralization, accountability.

3. According to the criteria and indicators of a blockchain token determined over the course of the research, a diagnostic methodology 
has been developed, as well as the questionnaire consisting of 18 questions, the answers to which allow comparing the characteristics of a blockchain token to those of a digital asset. The results of the questionnaire are evaluated based on the principle of the equivalence of categories of a digital asset, particularly the grouping of questions based on the criteria, and, therefore, allow determining how much characteristics of a blockchain token correspond to those of a digital asset.

4. The proposed mathematical formalization of the methodology for determining whether the characteristics of a blockchain token correspond to those of a digital asset allows stating the mathematical justification and reliability of this methodology. 


\section{THESAURUS}

Asset is property and/or (property, non-property) rights of a natural person and/or business entity, which represent value, including digital assets, money and various kinds of works, services.

Balance accounting of blockchain tokens is a method for registering and accounting transactions implemented by the software of the blockchain network node, which allows determining the difference between income and expenditure of units of account at a certain point in time at the address of their accounting.

Balance accounting of digital assets is a method for determining the difference between income and expenditure of digital assets at a certain point in time at the address of their accounting, which is based on the registration and accounting of transactions of a blockchain token and is implemented by the software of the blockchain network node.

Bernoulli formula represents a probability distribution for a number of occurrences of a random event in the final series of independent tests in the same conditions.

Blockchain is a distributed ledger, which constitutes a sequential chain of generated transaction blocks built according to certain rules. At the same time, each subsequent block of the structure contains information about the previous block, so on the whole, the chain stores the entire history of completed transactions.

Blockchain token is an accounting unit circulating in the distributed ledger by means of a transaction with a unique identifier.

Creator of a BT is an entity that directly or indirectly (as a customer) indicates the value, importance and usefulness of an object by creating an alphanumeric identifier that is registered in the blockchain and provides its owner with a certain amount of access rights to an information resource.

Cryptoasset is digital representations of value made possible by advances in cryptography and the distributed ledger technology; cryptoassets are denominated in their own units of account and can be transferred peer-to-peer without intermediaries. 
Cryptocurrency is a digital representation of value intended to create a peer-to-peer alternative to a legal payment instrument issued by the government; it is used as a general purpose means of exchange (independent from any central bank); backed by the mechanism known as cryptography; can be transformed into a legal tender and vice versa.

Cryptography is the science studying techniques to secure confidentiality (impossibility of reading information by a third party), data integrity (impossibility of imperceptible information change), authentication (verification of the author's authenticity or other object properties) as well as non-repudiation.

Currency is any commodity that can perform the function of money when exchanging goods on the domestic or international market.

Derivative of the right is a property of the object, giving its owner the right, which is formed from the right to a value.

Digital asset is an information resource derivative of the right to a value and circulating in the distributed ledger in the form of a unique identifier.

Distributed ledger technology is a new approach to recording and exchanging data among multiple data stores (also known as books and ledgers). This technology allows recording, sharing and synchronizing transactions and data in a distributed network of various network participants.

Document is digitally recorded information that establishes certain attributes and properties of a digital object, rules and conditions for its creation and circulation in an information system as well as the order of its execution. It also exists in an integrated form, which means that it represents a set of structurally independent digital documents that establish separate aspects, which, according to their primary purpose, regulate the document as a whole.

Electronic money is a specialized electronic impulse (file), which is recorded on a medium containing money characteristics and a quantitative representation of the value of the money equivalent, is a prepaid financial product, is issued after the issuer receives funds in an amount not less than the value of the money equivalent, and is the 
obligation of the issuer, which receives the right to claim the repayment by the owner of such money.

Financial system is an organizational form of monetary relations between all the subjects of the reproduction process of the distribution and redistribution of the gross national product.

Identifier of a blockchain token transaction (Identifier) is a unique set of alphanumeric characters of a certain length assigned to the transaction of a blockchain token in the environment of its circulation.

Information resource is information structured and organized in a certain way, recorded on a tangible medium. This information can be stored, transferred, used and replenished. The information resource has the properties of practical significance and usefulness, as well as the possibility of multiple use.

Jordan measure is the simplest and most natural way of determining the notions of length, area, volume of a set viewed as the same finite limit of sequences of upper and lower bounds of the sought value in the process when the positive measuring unit is approaching zero.

Property law is an absolute subjective civil right that provides an opportunity for its owner upon performing his/her direct actions to gain useful properties from the individually-defined thing (thing as such) for satisfying his/her own interest.

Terms and conditions of using a BT are the data displayed in an information resource that determine the underlying regularities, regulations and guiding principles for circulation of an alphanumeric identifier that is registered in the blockchain and provides its owner with a certain amount of access rights to an information resource.

Transaction hash is a fixed-length number that is mapped to data of arbitrary length in such a way that the probability of the appearance of different data with the same hash would tend to zero, and it would be hard to recover the data on their hash.

UTXO is an unspent transaction output that can be used as an input of a new transaction.

Value is worth, utility, or importance, which can also be expressed by different measurement units depending on the area of 
practical use of such a value and the ecosystem in which such a value exists.

Virtual asset is a representation of currency in some environment or situation. In this context, currency can be defined as either a medium of exchange or a property that has value in a specific environment. Monetary virtual assets are often called virtual currency.

Virtual currency is created property, which is accounted through the use of information and telecommunication technologies; not denominated in the currency of states, can be used by an indefinite number of persons to make payments, is not electronic money and legal tender.

Virtual money is an internal electronic currency of network communities, the application field of which is limited to the acquisition and sale of virtual goods within such a community. 


\section{REFERENCES}

1. European Central Bank. Virtual currency schemes. Frankfurt am Main: European Central Bank, 2012. 54 p. URL: https://www.ecb.europa.eu (Last accessed: 08.12.2018).

2. European Central Bank. Virtual currency schemes - a further analysis. Frankfurt am Main: European Central Bank, 2015. 38 p. URL: https://www.ecb.europa.eu (Last accessed: 08.12.2018).

3. Virtual currencies and beyond: Initial considerations/He D., etc. International Monetary Fund, 2016. $42 \mathrm{p}$. URL: https://www.imf.org (Last accessed: 11.11.2018).

4. Committee on Payments and Market Infrastructures. Digital currencies. Bank for International Settlements, 2015. $21 \mathrm{p}$. URL: https://www.bis.org (Last accessed: 19.11.2018).

5. European Banking Authority. Opinion on "virtual currencies". European Banking Authority, 2014. $46 \mathrm{p}$. URL: https://www.eba.europa.eu (Last accessed: 24.12.2018).

6. European Securities and Markets Authority. Warning on the risks of virtual currencies. URL: https://www.esma.europa.eu (Last accessed: 03.12.2018).

7. Natarajan H., Krause S. K., Gradstein H. L. Distributed ledger technology (DLT) and blockchain: Fintech Note no. 1. Washington, D. C.: World Bank Group. 2017. 60 p. URL: http://documents.worldbank.org (Last accessed: 07.12.2018).

8. Financial Action Task Force. Virtual currencies - key definitions and potential AML/CFT risks. Paris: FATF/OECD, 2014. 15 p. URL: http://www.fatf-gafi.org (Last accessed: 27.11.2018).

9. Houben R., Snyers A. Cryptocurrencies and blockchain: Legal context and implications for financial crime, money laundering and tax evasion. 2018. URL: http://www.europarl.europa.eu (Last accessed: 21.11.2018).

10. Vakhrushev D. S., Zhelezov O. V. Kriptovalyuta kak fenomen sovremennoi informatsionnoi ekonomiki: problemy teoreticheskogo osmysleniya. [Cryptocurrency as a Phenomenon of the Modern Information Economy: Problems of Theoretical 
Understanding] Naukovedenie - Science Studies. 2014. Issue 5(24). p. 4-15. [in Russian]

11. Xaurum Official. The difference between cryptocurrency and digital assets, and why should holders care? Medium: web portal. Last updated: 20.03.2018. URL: https://medium.com (Last accessed: 14.12.2018).

12. What is cryptocurrency: 21st-century unicorn - or the money of the future? Blockgeeks: web portal. Last updated: 13.09.2018. 22.12.2018).

13. Ahapova A. I., Sihaiov A. O. Vplyv kryptovaliut na finansovu systemu v Ukraini. [Impact of Cryptocurrencies on the Financial System in Ukraine] Suchasni problemy ekonomiky $i$ pidpryiemnytstvo - Modern Problems of Economy and Business. 2017. Issue 20. p. 134-141. [in Ukrainian]

14. Tanklevska N. S., Petrenko V. S., Karnaushenko A. S. Ekonomichna sutnist ta vydy kryptovaliuty u sviti. [Economic Essence and Types of Cryptocurrencies in the World] Biznesnavihator - Business navigator. 2017. Issue 4-2(43). p. 133-138. [in Ukrainian]

15. Cryptocurrency vs Blockchain: What's the difference? eToroX: website. URL: https://www.etorox.com (Last accessed: 07.01.2019).

16. Introduction to cryptocurrencies. Kraken: website. URL: https://www.kraken.com (Last accessed: 15.12.2018).

17. Abramchuk M. Y., Saltykova H. V., Bilous Y. G. Kryptovaliuta yak informatsiino-komunikatsiinyi instrument finansovo-ekonomichnykh vidnosyn: oblikovyi aspekt. [Cryptocurrencies as an Information and Communication Tool of Financial and Economic Relations: Accounting Aspect] Hroshi, finansy i kredyt-Money, Finances and Credit. 2018. Issue 18. p. 293 299. [in Ukrainian]

18. Understanding cryptocurrency: How it works, what drives it, should you buy it? Interesting Engineering: website. URL: https://interestingengineering.com (Last accessed: 27.12.2018). 
19. Voskresenskaya E. V. O neobkhodimosti pravovogo regulirovaniya virtual'nykh valyut. [About the Need of Legal Regulation of Virtual Currencies] Vestnik Omskoi yuridicheskoi akademii - Newsletter of Omsk Law Academy. 2018. V. 15. No. 2. p. 148-151. doi:10.19073/2306-1340-2018-15-2-148-151. [in Russian]

20. Braddick K., Bailey A., Ramsden D. Cryptoassets taskforce: Final report.

2018. URL: https://gov.uk/government/publications (Last accessed: 11.12.2018).

21. He D. Monetary Policy in the Digital Age. Finance and Development. 2018. Vol. 55. Iss. 2. P. 13-16. URL: https://www.imf.org/external/pubs/ft/fandd/2018/06/centralbank-monetary-policy-and-cryptocurrencies/he.pdf (Last accessed: 03.09.2018).

22. The Tech Dictionary and IT Encyclopedia. TechTarget: website. URL: https://whatis.techtarget.com (Last accessed: 15.12.2018).

23. Proekt Zakonu Ukrainy "Pro vnesennia zmin do Podatkovoho kodeksu Ukrainy shchodo opodatkuvannia operatsii z virtualnymy aktyvamy v Ukraini”: vid 14.09.2018 № 9083 [The Draft Law of Ukraine "On amendments to the tax code of Ukraine in relation to taxation of transactions with virtual assets in Ukraine: Dated 14.09.2018 No. 9083] // Inform-pravova systema "Liha-Zakon"/VR Ukrainy - Information and Legal System "League-Law"/VR of Ukraine.

URL: http://search.ligazakon.ua/1_doc2.nsf/link1/JH70B00A.html (L ast accessed: 05.11.2018). [in Ukrainian]

24. What exactly is a digital asset \& How to get the most value from them? MerlinOne: website. URL: https://merlinone.com (Last accessed: 22.12.2018).

25. Windsor R. Defining Digital Assets. Digital Asset News: web portal. Last updated: 11.08.2017. URL: https://digitalassetnews.org (Last accessed: 21.12.2018). 
26. Medhat M. Digital asset management and IoT - the innovation path from "digits" to "value". CIOReview: website. URL: https://www.cioreview.com (Last accessed: 10.12.2018).

27. Dyudikova E. I Perspektivy razvitiya elektronnykh deneg kak elementa natsional'noi platezhnoi sistemy Rossiiskoi Federatsii: avtoref. diss. na soiskanie uch. stepeni kand. ekon. nauk: 08.00.10. [Prospects of Development of Electronic Money as an Element of National Payment System of the Russian Federation] Stavropol. 2017. 28 p. [in Russian]

28. Protsenko A. T. Pravove rehuliuvannia obihu elektronnykh hroshei v Ukraini: dys. ... kand. yur. nauk: 12.00.07 [Legal Regulation of the Circulation of Electronic Money in Ukraine] / Mizhrehionalna akademiia upravlinnia personalom - Cross-Regional Academy of Personnel Management. Kyiv, 2016. 202 p. [in Ukrainian]

29. Kud A. A. Substantiation of the Term "Digital Asset": Economic and Legal Aspects. International Journal of Education and Science. 2019. Vol. 2. No. 1. P. 41-52. doi:10.26697/ijes.2019.1.06

30. Kud A., Pypenko I. Social and Economic Foundation of the Implementation of Blockchain-Based Systems of Digital Assets in Developing Countries. International Journal of Education and Science: Conference Abstracts. 2018. Vol. 1. No. 3-4. P. 30. doi:10.26697/ijes.2018.3-4.30 
Notes 
Методика діагностики токену блокчейну на відповідність цифровому активу

Методичний посібник

(Англ. мовою)

КУДь Александр Александрович

ISBN 978-617-7089-07-9

DOI 10.26697/9786177089079.2019

Видасться в авторській редакції

Відповідальний випусковий: І. С. Пипенко

Комп'ютерне складання та верстання: Я. Ю. Свячена

Формат $80 \times 64 \frac{1}{6}$

Гарн. «Тimes». Папір мелований. Друк офсетний.

Ум. друк. арк. 3,0. Зам. № 1-25.

Тираж 5000 пр.

Науково-дослідний інститут ХОГОКЗ

Харківська обласна громадська організація "Культура Здоров'я"

Україна, 61105, м. Харків, пров. Забайкальський, 6/6.

http://publisher.culturehealth.org; тел./факс: (057)775-75-23.

Emails: CultureHealth@ukr.net; KOSOCH@gmail.com;

Свідоцтво про державну реєстрацію видавництва ДК № 4387 від 10.08.2012 